\title{
REFLEXÕES SOBRE O ACESSO A EQUIPAMENTOS CULTURAIS POR PARTE DO CORPO DISCENTE DO INSTITUTO FEDERAL DO RIO DE JANEIRO - CAMPUS SÃO GONÇALO
}

\author{
Erick Nimrichter \\ Instituto Federal do Rio de Janeiro, Brasil \\ Hayla Thami Lage \\ Instituto Federal do Rio de Janeiro, Brasil \\ Natália Cabral Muniz \\ Instituto Federal do Rio de Janeiro, Brasil
}

\begin{abstract}
Resumo: O acesso a bens culturais é uma questão que requer destaque, já que está diretamente ligado ao desenvolvimento e à construção do indivíduo como ser social. Por essa razão, o Instituto Federal do Rio de Janeiro, campus São Gonçalo, sendo uma instituição de ensino, tem a função de ser cenário de discussões deste acesso por parte de seu corpo discente. Através de questionários, foi possível mapear a relação entre os bens culturais e os alunos de nossa unidade, com o propósito de verificar se o município de São Gonçalo oferece infraestrutura no que diz respeito aos equipamentos de cultura e, além disso, à consolidação do papel da escola na relação entre indivíduo e sua formação social.
\end{abstract}

Palavras-chave: políticas culturais, pesquisa, extensão, acesso, bens culturais.

\section{INTRODUÇÃO}

O presente trabalho desponta, na realidade, da relação entre extensão e pesquisa, visto que o projeto ETC \& TAL é uma atividade cultural implementada no Instituto Federal do Rio de Janeiro - Campus São Gonçalo (IFRJ-SG) - cuja proposta é a relação entre extensão e pesquisa, permitindo, assim, um olhar que vai do plano prático ao acadêmico. Diante disso, para elucidar a proposta inicial do trabalho em questão, é de suma importância compreender que sua execução depende do projeto original que, por sua vez, propõe-se a desenvolver oficinas divididas em três grandes correntes temáticas: leitura, cinema e teatro. Os principais objetivos dessas oficinas são (a) efetuar atividades periódicas de leitura; (b) fomentar encontros para análise e debate de filmes; e (c) trabalhar noções de teatro no que diz respeito à produção de textos 
dramatúrgicos e a prática da interpretação teatral. Portanto, ETC \& TAL tem o papel de agente cultural para o corpo discente do IFRJ-SG.

Tendo em vista o trabalho de extensão descrito acima, pensamos em um projeto científico procedente do entrelaçamento entre a proposta extensionista a que pretendemos nos dedicar e a pesquisa acadêmica. O seu principal objetivo é colectar dados sobre a relação entre o aluno residente no município de São Gonçalo e seu acesso aos equipamentos culturais dessa mesma região.

Além de desenvolver ações práticas através das oficinas descritas, tem como procedimentos os seguintes: (a) fazer um levantamento de caráter sócio-cultural através de questionários, verificando o grau de envolvimento dos jovens com atividades extracurriculares; (b) realizar a avaliação dos resultados da pesquisa de opinião com propósito de melhor atender às demandas de nossas oficinas; (c) propor atividades, como palestras, mesas-redondas, novas oficinas e encontros culturais, de maneira a dar conta dos anseios de nossos alunos, tendo como base, primeiramente, o resultado de nosso questionário avaliativo e, também, as sugestões feitas pelo próprio corpo discente durante nossas ações de extensão; (d) traçar o perfil do estudante da unidade São Gonçalo, a fim de verificar os aspectos que facilitam ou dificultam o acesso aos bens culturais oferecidos pelo referido município; e (e) ampliar os limites do projeto para atuação do mesmo na comunidade que vive no entorno do IFRJ-SG.

Dessa forma, nosso projeto visa a realizar a integração entre as atividades acadêmicas e as de cunho prático, levando em conta o perfil de nossos alunos e da comunidade de São Gonçalo para melhor atender às demandas culturais deste município. Com a intenção de expor melhor tal proposta, organizamos o presente artigo nas seguintes subseções: em (1), apresentamos do projeto de extensão a partir do qual esta pesquisa acadêmica baseia-se; em (2), descrevemos a metodologia científica utilizada para desenvolver os dados deste trabalho; em (3) analisamos os resultados da pesquisa; e, por último, em (4) discorremos algumas considerações finais sobre o tema abordado.

\section{O PAPEL EXTENSIONISTA DO PROJETO ETC \&TAL}

O projeto intitulado ETC \& TAL constitui-se em uma prática extensionista evidenciada através da promoção de eventos e oficinas, sobretudo, ligados, à leitura, ao cinema e ao teatro. A ideia desse projeto nasceu através da observação, por parte de um grupo de alunos do IFRJ-SG, sobre o acesso escasso a equipamentos culturais ou à programações de cunho cultural no município Este grupo composto por onze estudantes e um professor-orientador começa a formar-se, com o objetivo de atender às demandas por discussões, debates, isto é, atividades em geral que não tratassem apenas de questões 
de ordem acadêmica, mas também e, principalmente, de temas culturais em seu sentido mais latu. Assim, funda-se o ETC \& TAL. O primeiro passo tomado foi a organização de três grandes oficinas de funcionamento regular tendo cada uma delas recebido um nome e constituindo-se num GT (grupo de trabalho) específico.

O LITTERA, o nosso grupo de literatura, propõe um livro para a leitura mensal aos alunos do IFRJ-SG. A leitura é divulgada com cerca de 20 dias de antecedência, e os alunos que sentirem interesse na obra escolhida devem se inscrever para o debate a ser realizado com agendamento prévio. O grupo de trabalho dessa oficina tem de ler previamente o livro sugerido e, com auxílio da professora-orientadora, elencar temas, oriundos da leitura, para fomentar o debate que, obviamente, é entremeado com a visão de cada leitor inscrito em nossa oficina. Essa oficina espraia seus domínios ao propor, além da atividade mensal, alguns encontros com autores e suas obras, como ocorreu com (a) o escritor Aleksander Henryk Laks ( $O$ sobrevivente e Mengele me condenou a viver), cujo principal tema a ser discutido foi a questão do Holocauto a partir da visão do oprimido e não do opressor; (b) o escritor Marco Simas (Bárbara não quer perdão; Último trem e Identidade), que nos auxiliou na discussão acerca das relações sociais entre os indivíduos geridas por temas como o coronelismo em cidade ditas pequenas; e (c) o escritor Raphael Montes (Suicidas; Dias Perfeitos), que nos possibilitou mostrar aos alunos a literatura nacional contemporânea em franca ascensão no cenário internacional, uma vez que Montes tem sido considerado o grande inovador da nossa literatura policial. Esta oficina literária oferece, pois, aos alunos um espaço de constante discussão sobre a literatura nacional e estrangeira, a fim de despertar o hábito de ler, a busca pelo novo e a constante reflexão sobre o papel da literatura na formação de cidadãos críticos. Este tipo de práticas torna a leitura mais atrativa e não apenas condicionada a avaliações, como ocorre frequentemente em escolas de todo o Brasil.

Outra oficina oferecida aos alunos do IFRJ-SG é a de cinema, denominada CLACKET. Esta tem como objetivo exibir um filme e realizar um posterior debate sobre a sua temática norteadora. Esse debate é feito por um convidado que tenha alguma relação com o tema abordado. A ideia inicial é trazer produções que não sejam comuns ao circuito comercial e também algumas mais populares, mas sob um ponto de vista mais crítico. Todo o corpo discente do campus foi convidado a participar dessa atividade e, em geral, também temos tido a participação de grande parte do corpo docente, o que gerou um excelente encontro e discussão para a comunidade do Instituto Federal. A oficina é realizada mensalmente, mas em alguns meses exibimos mais de uma 
produção, visto que alguns professores sugerem debates e atividades e, sempre que possível, as incorporamos ao projeto.

A nossa terceira oficina é a de teatro: ARCHARIUS. Esta se desenvolve através de encontros semanais e se diferencia das outras oficinas propostas, uma vez que, muito embora tenha o auxílio de alguns profissionais de teatro e de uma professora de nossa unidade, o próprio grupo de alunos envolvidos no projeto ministram as aulas. Uma vez por mês, os alunos do curso de teatro, inscritos conforme ordem de chegada, têm uma aula "formal" com um profissional de dramaturgia e, nas semanas posteriores, os integrantes do projeto propõem atividades baseadas no que foi ensinado na primeira aula do mês aos alunos inscritos. Este formato gera uma grande troca de experiências entre atores e não atores, explicitando aos interessados que a oficina de teatro é para não atores. A oficina tem duração total de um semestre, abrindo-se de seguida a inscrição para novos alunos. Atualmente, em virtude de já termos oferecido a oficina por alguns semestres, o ARCHARIUS está mudando seu perfil de atuação e, em vez de atuar em formato de oficina para não atores, estamos formando um grupo de dramaturgia cujo objetivo é a adaptação de textos consagrados de autores nacionais como Ariano Suassuna, e a posterior apresentação dessas peças a todo o corpo de funcionários e alunos de nossa unidade. Nosso objetivo final será tornar essas apresentações itinerantes para que possamos abraçar escolas públicas do entorno de nossa unidade com alguns encontros de teatro. Cumpre salientar, entretanto, que, como o projeto não tem financiamento regular, nos valemos de cenários, figurinos e equipamentos improvisados, o que torna possível que as apresentações sejam em espaços mais flexíveis, abraçando assim mais tipos de públicos.

Além dessas oficinas regulares, conforme mencionado anteriormente, o referido projeto promove também outros eventos, como, por exemplo, palestras. Em uma delas, recebemos a professora doutora Rosângela Gomes Ferreira com o objetivo de discutir a estrutura de textos dissertativo-argumentativos e seus critérios básicos de avaliação, já que este tipo de textos é essencial por frequente nas atividades acadêmicas. Outras atividades propostas são os bazares culturais, que têm o objetivo de trazer livros a preços mais acessíveis aos alunos. Aqueles são todos angariados por meio de doações e a verba arrecadada em nossos bazares serve de subsídio para o projeto.

Em síntese, o presente grupo de trabalho foi pensado com objetivo de tornar o espaço escolar um lugar de ampla discussão, um lugar dinâmico que permita o aluno trocar experiências e se tornar um cidadão mais engajado nas questões do mundo, aprimorando, assim, a formação do corpo discente do IFRJ-SG. Durante a execução das atividades, pudemos perceber que muitos alunos viam o projeto como única fonte de 
acesso à cultura, conceito aqui entendido de maneira mais restrita, já que todo indivíduo traz para sua escola a sua cultura desenvolvida através de suas experiências pessoais e sociais. Neste texto estamos adotando a palavra "cultura" vinculando-a a equipamentos culturais, como detalharemos mais adiante. Levando em consideração esta observação, decidimos avaliar o perfil cultural dos alunos do campus São Gonçalo através de um questionário, como veremos na seção seguinte.

\section{DA PRÁtica À PESQUiSA: ANÁlise do PERFIL CULTURAL DOS ESTUDANTES DO IFRJ - CAMPUS SG}

Com o objetivo de avaliar o perfil do corpo discente do IFRJ-SG em relação ao acesso aos bens culturais, elaboramos um questionário que foi disponibilizado online ${ }^{1}$, onde os alunos puderam-nos informar com qual frequência costumam ir a cinemas, teatros, museus, apresentações e eventos culturais e a localidade desses espaços. Ele foi elaborado com auxílio de uma ferramenta eletrônica - o Google Drive - e o link para acesso foi postado na página do Facebook que engloba todos os alunos de nível médio do curso técnico em Química de nossa unidade, que conta com cerca de duzentos e cinquenta sujeitos com matrícula ativa. Desse total, a amostra definitiva foi de cento e nove $(\mathrm{T}=109)$ que se dispuseram a participar do questionário e cujas respostas foram analisadas.

Deve-se destacar, no que tange aos números, que nosso teste não revela ainda, um parâmetro predominante em relação ao número de estudantes, porém o nosso objetivo principal é ter, ao menos, uma análise-piloto para que seja possível formar parcerias e ampliar a amostra da nossa pesquisa e, mais, gostaríamos que a participação fosse espontânea e não obrigatória.

No questionário foram apresentadas quinze perguntas, sendo catorze de múltipla escolha e uma de resposta aberta. Nas respostas de múltipla escolha foi apresentada uma escala de frequência de uso/acesso, a possibilidade de marcar mais de uma opção.

O primeiro passo analítico foi computar as questões gerais que revelam o local onde residem e a faixa etária de nossos alunos. Após isso, fizemos a categorização e o tratamento de cada questão e, por último, estabelecemos contrastes e comparações, para que fosse possível, assim, obter um perfil dos estudantes de nível médio do IFRJSG residentes em São Gonçalo, conforme apresentaremos na seção seguinte.

\section{O QUE DIZER, ENTÃO, DO ACESSO AOS EQUIPAMENTOS CULTURAIS?}

${ }^{1}$ Questionário disponível através do endereço: http://goo.gl/forms/48tUD5SQlI 
Para realizar a análise dos dados obtidos através do estudo, é preciso discorrer acerca de alguns fatores que estão atrelados aos termos "cultura" e "bens culturais". Segundo (DaMatta, 2010), a palavra cultura pode ser carregada de valores pouco comprometidos com a real essência do termo, como quando se julga cultura como algo ligado diretamente à intelectualidade. Ocorre também de a ideia de cultura estar atrelada à setorização dos grupos de indivíduos de acordo com suas tradições e costumes, o que deveria ser aceitável, a não ser pelo fato de isso ocorrer, predominantemente, de forma discriminatória, culminando numa supremacia de certo grupo que possui seus costumes privilegiados.

Dessa forma, frisamos que conceitos de cultura reproduzidos e aplicados pelo senso comum, como, por exemplo, em se tratando da hierarquização de indivíduos através de questões relativas à intelectualidade, bem como a segregação de grupos por meio de crenças ou tradições, conforme citado acima, não representam a ideia de cultura com a qual este trabalho soma forças.

Adotamos, sim, a visão de que cultura está pautada num mapa de códigos através do qual certo grupo, indivíduo ou sociedade lança mão para viver e se inserir no mundo, como se observa em DaMatta (2010: 4), a seguir:

O conceito de cultura, ou, a cultura como conceito, então, permite uma perspectiva mais consciente de nós mesmos. Precisamente porque diz que não há homens sem cultura e permite comparar culturas e configurações culturais como entidades iguais, deixando de estabelecer hierarquias em que inevitavelmente existiriam sociedades superiores e inferiores.

Não é a finalidade deste estudo restringir os significados do "conceito de cultura" e de "bem cultural", visto que só fizemos a análise de quatro (cinema, teatro, museus e/ou centros culturais e apresentações em geral) dos tantos possíveis; nem mesmo buscamos definir o que seja cultura, uma vez que uma atividade cultural é toda a experiência de um indivíduo no mundo e é originária de suas vivências, como descreveu o Instituto Estadual do Patrimônio Histórico e Artístico de Minas Gerais (IEPHA) (2014: 1):

Em seu sentido amplo, [bem cultural] compreende todo testemunho do homem e seu meio, apreciado em si mesmo, sem estabelecer limitações derivadas de sua propriedade, uso, antiguidade ou valor econômico. Os bens culturais podem ser divididos em três categorias: bens naturais, bens materiais e bens imateriais.

Em síntese, nossa proposta é analisar a distribuição desses bens em São Gonçalo, verificando seu real acesso por parte de uma parcela de residentes representada pelos alunos de nosso campus escolar. 
Como discorrido na seção anterior, temos uma amostra de cento e nove estudantes que participaram do questionário que disponibilizamos para descrever o perfil cultural dos alunos do IFRJ-SG. Esses estudantes são distribuídos da seguinte maneira.

A faixa etária apresentada no gráfico 1 mostra que esta varia de quinze a dezenove anos, sendo predominante a faixa referente aos dezesseis e dezessete anos.

\section{Gráfico 1: Distribuição dos alunos por idade $(T=109)$}

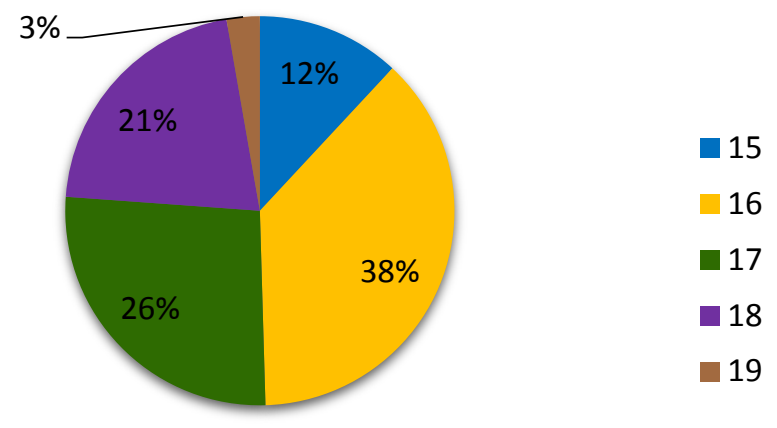

No gráfico 2, verificamos que, do total de alunos participantes, $61 \%$ correspondem a estudantes do sexo feminino e, portanto, o restante, ao masculino.

\section{Gráfico 2: Distribuição dos alunos por gênero $(T=109)$}

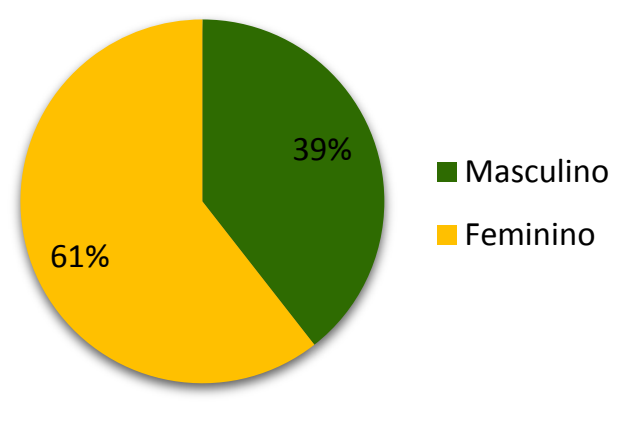

E, finalmente, no gráfico 3, constatamos que a maioria de nossos alunos reside no município de São Gonçalo, 60\%, razão pela qual tratar da região é uma prioridade neste estudo. 


\title{
Gráfico 3: Distribuição dos alunos por cidades onde residem $(T=109)$
}

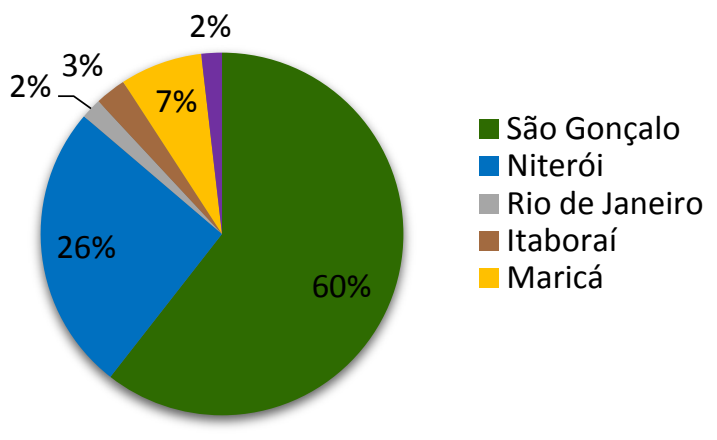

Para uma primeira análise, levamos em conta as respostas totais que revelam certa dificuldade de acesso dos estudantes aos equipamentos culturais, uma vez que, com exceção do cinema, quem tem uma frequência mensal de uma vez por mês como predominante (V. Gráfico 4):

\section{Gráfico 4: Frequência de acesso ao cinema $(T=109)$}

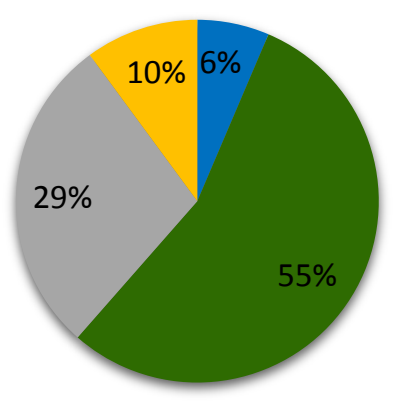

\author{
Nenhuma vez \\ ao mês \\ 1 vez ao mês \\ 2 a 3 vezes ao \\ mês \\ Mais de 3 vezes \\ ao mês
}

Nos demais bens culturais, prevalece "nenhuma vez ao mês" como principal resposta, como podemos ver nos gráficos 5, 6 e 7:

\section{Gráfico 5: Frequência de acesso ao teatro $(T=109)$}
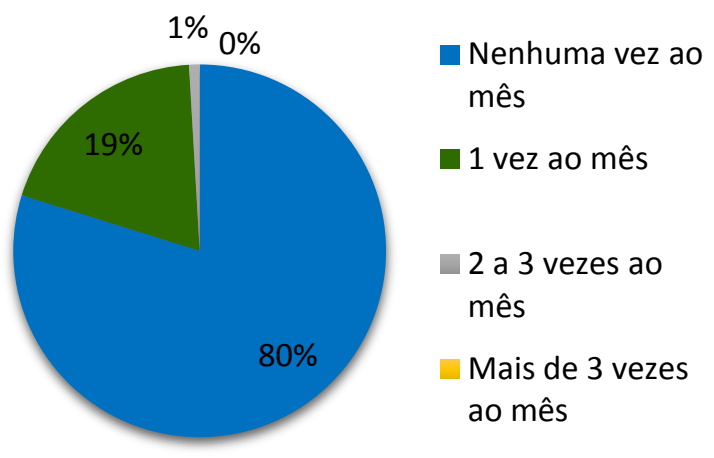
ao mês 


\section{Gráfico 6: Frequência de acesso a museus e/ou a centros culturais $(T=109)$}

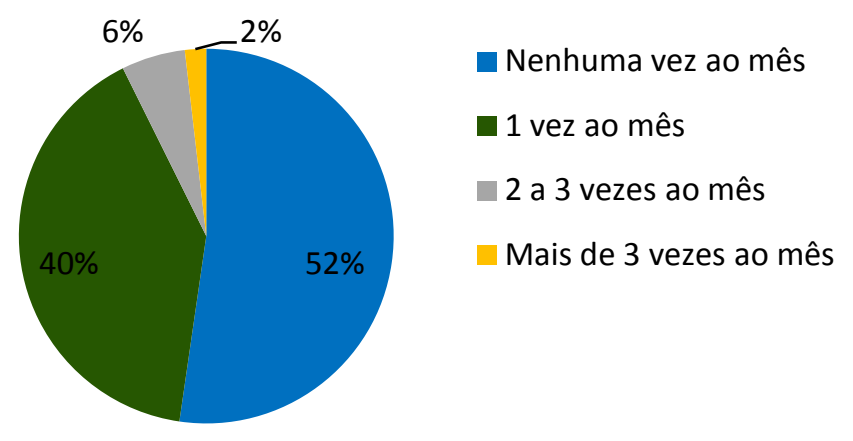

\section{Gráfico 7: Frequência de acesso a shows de variados formatos $(T=109)$}

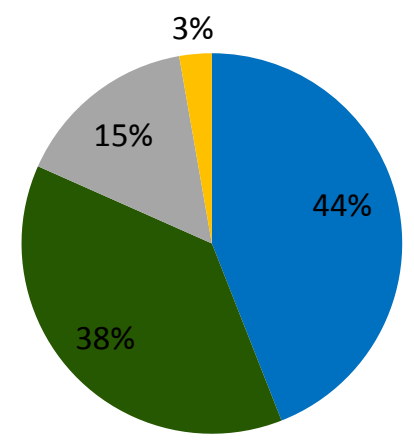

Nenhuma vez ao mês

$\square 1$ vez ao mês

2 a 3 vezes ao mês

Mais de 3 vezes ao mês

Tendo presente os dados expostos nos vários gráficos, nota-se que mais que a maioria dos alunos frequentam cinemas com uma periodicidade de "uma vez ao mês", destoando, assim, dos outros cenários de equipamentos que estão representados nos gráficos 5, 6 e 7, cuja percentagem, em relação à frequência "nenhuma vez ao mês" é igual a $80 \%, 52 \%$ e $44 \%$, respectivamente.

Pode-se justificar essa grande diferença entre os cenários pelo boom das construções de shopping centers, passando, assim, a haver complexos cinematográficos e não mais apenas salas de exibição normalmente localizadas em ruas e/ou galerias. Esse tipo de espaço comercial tornou-se a primeira opção de lazer e acesso a bens culturais na visão da maioria da população, fazendo com que, dentre dos equipamentos citados, o cinema seja mais visitado do que outros.

Refletindo sobre isso, conclui-se que a partir do não investimento governamental no que diz respeito à relação entre população e cultura, surja, uma aceitação passiva da privatização de um espaço que deve ser público, como expressam Melo \& Peres (2006: 7): 
Ampliam-se os complexos de diversão (com o surgimento de shoppings, parques temáticos, casas de shows, entre outros), entretanto, aparentemente cada vez mais se organizam locais públicos para privilegiados, onde, implícita ou explicitamente (por motivos diversos, entre os quais o preço e a distância), definem-se as possibilidades (restritas) de acesso. Hierarquiza-se (e privatiza-se) o espaço urbano.

Levando em conta a percentagem de $60 \%$ de alunos residentes em São Gonçalo, priorizamos, neste estudo, a situação dessa grande cidade. Com isso, especificamos, quantitativamente, seus bens culturais. Segundo a Secretaria Municipal de Turismo e Cultura (SMTC), os equipamentos administrados e/ou fomentados pelo poder público são os seguintes (V. Quadro 1):

\section{Quadro 1: Bens culturais administrados e/ou fomentados pelo poder público}

\begin{tabular}{|c|}
\hline Casa das Artes Villa Real (Bairro: Centro) \\
\hline Escola de Música Pixinguinha (Bairro: Barro Vermelho) \\
\hline Teatro Carequinha (Bairro: Neves) \\
\hline Centro Cultural Joaquim Lavoura (Bairro: Estrela do Norte) \\
\hline Lona Cultural Lídia Maria da Silva (Bairro: Jardim Catarina) \\
\hline Espaço Carequinha (Bairro: Centro) \\
\hline
\end{tabular}

Por serem poucos os bens administrados pelo poder público em São Gonçalo e por estes não receberem uma divulgação efetiva, o mapeamento de todos os equipamentos da cidade torna-se difícil. Somando-se a isso o fato de não haver uma política de mapeamento de todos os bens culturais da cidade, torna-se ainda mais árdua a tarefa de verificar de que recursos culturais nossos alunos dispõem efetivamente. Enumerados os bens culturais públicos da cidade, é possível tecer um parecer insatisfatório acerca do panorama desses equipamentos na segunda maior cidade, em número de habitantes, do estado do Rio de Janeiro - aproximadamente um milhão, segundo o Censo de 2013 do IBGE (Instituto Brasileiro de Geografia e Estatística). De um modo geral, os bens supracitados distribuem-se apenas por cinco bairros de uma cidade que tem o total de noventa e cinco, constatando-se a defasagem na política cultural do município. 
Levando em conta a diminuta quantidade de equipamentos disponíveis na cidade, é cabível levantar outra questão: o deslocamento feito pelos estudantes residentes em São Gonçalo para acessar os bens culturais, conforme é elucidado pelos gráficos seguintes.

Dando o devido foco ao acesso a cinemas e apresentações culturais em geral, não há fluxo migratório da cidade de São Gonçalo para outras vizinhas. Isso se baseia no fato da existência de complexos cinematográficos juntamente com a possibilidade de, em feriados e festividades, existirem apresentações gratuitas ou de baixo custo, viabilizando, assim, o acesso a esses equipamentos dentro de São Gonçalo, de acordo com os depoimentos dos alunos (V. Gráfico 8).

\section{Gráfico 8: Cidades escolhidas pelos residentes de S. Gonçalo para aceder ao cinema $(T=109)$}

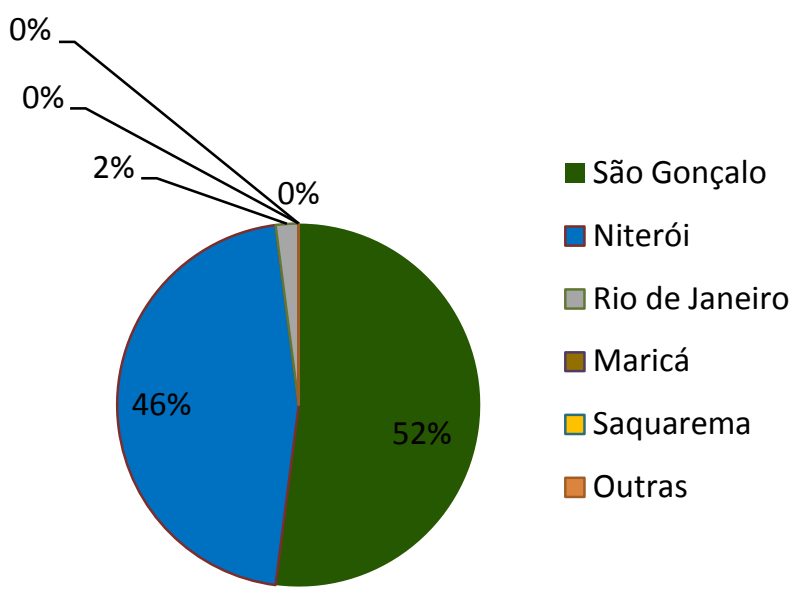

Em relação ao acesso a teatros, a museus e a centros culturais, a situação difere bastante da anterior (V. Gráficos 9 e 10)

\section{Gráfico 9: Cidades escolhidas pelos residentes de S. Gonçalo para aceder ao teatro}

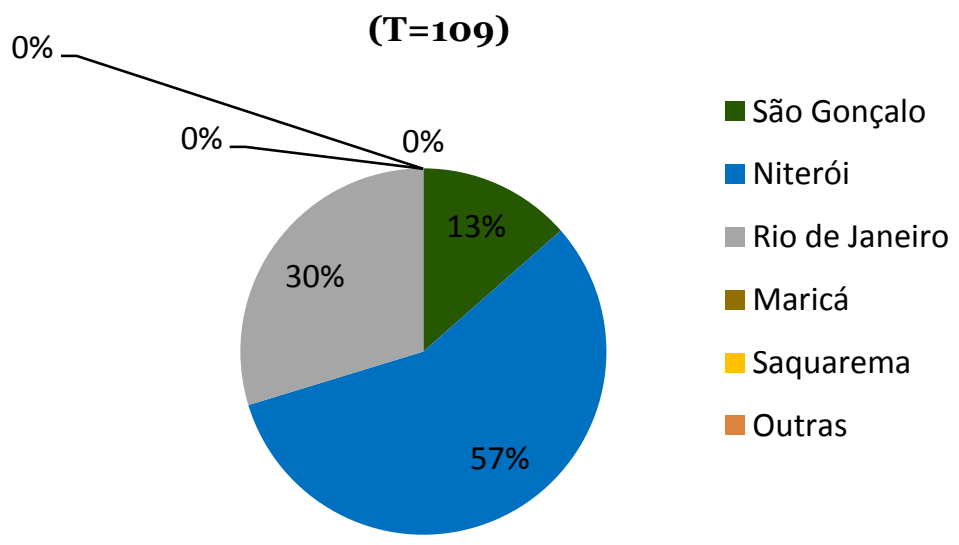




\section{Gráfico 10: Cidades escolhidas pelos residentes de S. Gonçalo para aceder a shows de variados formatos $(T=109)$}

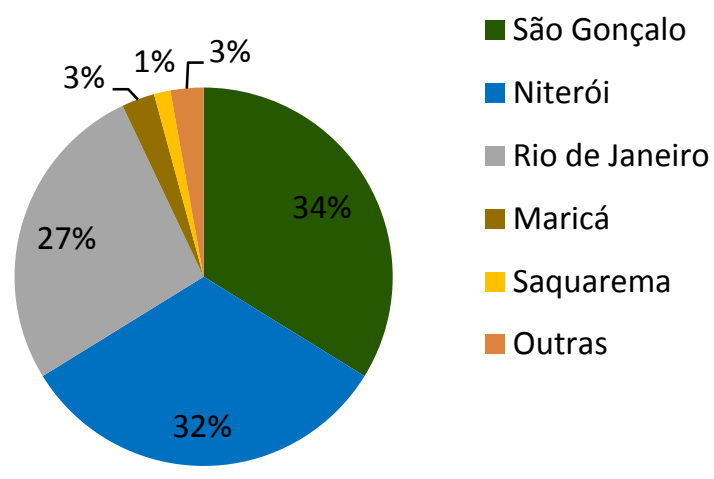

Como visível, a maior parte dos estudantes vai à procura desses espaços em outras cidades como Niterói e Rio de Janeiro. Dessa forma, numa análise rápida, pode-se perceber que há uma oferta maior de bens culturais nestas cidades, fato que pode ser explicado por uma questão econômica e de prestígio político.

Baseados nesses dados preliminares, podemos concluir, então, que, para que tenham acesso a equipamentos culturais, os nossos estudantes precisam, majoritariamente, deslocarem-se de sua cidade de origem para chegar a outros municípios, em geral, prestigiados economicamente. Esse deslocamento tem duas consequências relevantes. A primeira é o próprio reflexo da condição sócio-econômica de São Gonçalo, que revela pouco investimento em cultura; muito embora reconheçamos um esforço atual para promover mais atividades gratuitas destinadas à população residente em São Gonçalo, ainda há pouca divulgação desses eventos. A segunda diz respeito ao alto custo para os habitantes desse município em ir a eventos culturais em outras cidades, uma vez que, além de gastar dinheiro com a atividade em si (quando esta não for gratuita), e no transporte. Para os alunos de nossa unidade escolar, e mesmo os estudantes que residem em São Gonçalo, na maioria dos casos dependem de mais de uma condução para chegar à escola e, com isso, o auxílio financeiro de transporte não cobre nem as despesas referentes à ida ao colégio, muito menos atividades culturais externas ao planejamento letivo, mesmo que fundamentais para a formação de cidadãos críticos.

Assim, o nosso projeto de extensão - ETC \& TAL, descrito nas seções anteriores, entra em cena como uma forma de tornar a escola um pólo difusor de cultura num espaço em que o acesso aos equipamentos culturais é bastante limitado. 


\section{CONSIDERAÇÕES FINAIS}

Estamos cientes de que este tipo de análise não institui um cenário final de acesso a bens culturais em qualquer localidade. Por isso, existem medidas já tomadas para aprimorar este trabalho, como, por exemplo: a ampliação da amostra; uma análise mais profunda das razões que favorecem o deslocamento dos estudantes para outros pólos culturais; o mapeamento de outras regiões que não apenas São Gonçalo, uma vez que temos estudantes que residem em Maricá, Saquarema, Itaboraí, Niterói e outros municípios; a implantação de novas atividades culturais abertas à comunidade externa, e o traçar de um mapa mais real de todos os equipamentos disponíveis nas cidades que fazem parte de nosso estudo.

Entretanto, já podemos tecer algumas considerações finais sobre a nossa análise. A primeira diz respeito ao fato de que foi possível identificar um cenário desigual no que concerce ao oferecimento de bens culturais dentro de cidades importantes da região metropolitana do estado do Rio de Janeiro, considerando o seu número de habitantes ou o nível de desenvolvimento econômico.

A cidade de São Gonçalo, lócus desta análise, tem a necessidade de um investimento em políticas culturais, não apenas por possuir um grande número de habitantes e capacidade de crescimento econômico a longo prazo, mas também pelo fato de o sucateamento das áreas de cultura, lazer e entretenimento ser um dos grandes percauços vividos pelos moradores da região, para além de melhorias a se fazer na área de educação, saúde, meio ambiente, etc.

O nosso trabalho tem apenas o papel de marco inicial para fomentar discussões dentro e fora do IFRJ-SG em relação à demandas internas e externas, ou seja, de estudantesresidentes e da comunidade do entorno, sobre questões de suma importância atreladas à cultura e, consequentemente, ao desenvolvimento do município.

\section{REFERÊNCIAS BIBLIOGRÁFICAS}

Botelho, Isaura (s/d) Os equipamentos culturais na cidade de São Paulo: um desafio para gestão pública. http://www.fflch.usp.br/centrodametropole/antigo/v1/pdf/espaco debates.pdf (Último acesso em 02 de julho de 2014). 
DaMatta, Roberto (2010) Você tem cultura?.

http://naui.ufsc.br/files/2010/og/DAMATTA voce tem cultura.pdf (Último acesso em 20 de setembro de 2014).

Grunberg, Evelina (s/d) Educação Patrimonial - Utilização dos Bens Culturais como Recursos Educacionais.

http://www.pead.faced.ufrgs.br/sites/publico/eixo4/estudos sociais/educacao patri monial.pdf (Último acesso em 02 de julho de 2014).

Instituto Estadual do Patrimônio Histórico e Artístico de Minas Gerais (s/d) Sobre cultura e patrimônio cultural. http://www.iepha.mg.gov.br/sobre-cultura-epatrimonio-cultural (Último acesso em 27 de maio de 2014).

Melo, Victor Andrade de \& Peres, Fabio de Faria (2006) Espaço, lazer e política: desigualdades na distribuição de equipamentos culturais na cidade do Rio de Janeiro. Lecturas: Educación física y deportes. http://www.efdeportes.com/efd93/rio.htm (Último acesso em 01 de julho de 2014).

Erick Nimrichter é aluno do Curso Técnico Integrado em Química no Instituto Federal do Rio de Janeiro (IFRJ), bolsista dos Programas Institucionais de Bolsas de Iniciação Científica e Tecnológica (PIBICT) do convênio IFRJ/CNPq e membro do Grupo de Pesquisa "Literatura, Arte e Ciência". nimrichter.erick@gmail.com

Hayla Thami Lage é Graduada em Letras, Português-Espanhol, pela Universidade Federal do Rio de Janeiro (UFRJ), Doutora em Letras Vernáculas pela Universidade Federal do Rio de Janeiro (UFRJ), membro do NEMP/UFRJ (Núcleo de Estudos Morfossemânticos do Português) e professora de Língua Portuguesa do Instituto Federal do Rio de Janeiro (IFRJ). hayla.silva@ifrj.edu.br

Natália Cabral Muniz é aluna do Curso Técnico Integrado em Química no Instituto Federal do Rio de Janeiro (IFRJ), bolsista dos Programas Institucionais de Bolsas de Iniciação Científica e Tecnológica (PIBICT) do convênio IFRJ/CNPq e membro do Grupo de Pesquisa "Literatura, Arte e Ciência". nataliacabralmuniz@gmail.com

AGRADECIMENTOS: Ao Instituto Federal do Rio de Janeiro (IFRJ) e ao Conselho Nacional de Desenvolvimento Científico e Tecnológico (CNPq) pelos apoios financeiros. 